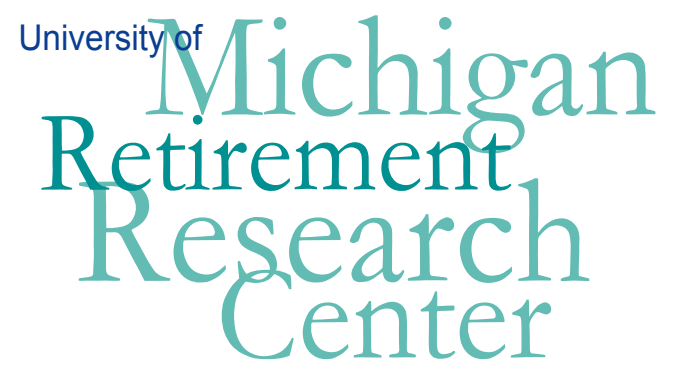

Working Paper

WP 2001-011

\title{
Eligibility for Social Security Disability Insurance
}

Olivia S. Mitchell and John W.R. Phillips

\begin{tabular}{|l|l|}
\hline $\mathrm{M}$ & $\mathrm{R}$ \\
\hline $\mathrm{R}$ & $\mathrm{C}$
\end{tabular}$\quad$ Project \#: UM00-06 


\title{
"Eligibility for Social Security Disability Insurance"
}

\author{
Olivia S. Mitchell \\ University of Pennsylvania and NBER \\ John W.R. Phillips \\ Social Security Administration
}

\author{
June 2001 \\ Michigan Retirement Research Center \\ University of Michigan \\ P.O. Box 1248 \\ Ann Arbor, MI 48104 \\ www.mrrc.isr.umich.edu \\ (734) 615-0422
}

\section{Acknowledgements}

This work was supported by a grant from the Social Security Administration through the Michigan Retirement Research Center (Grant \# 10-P-98358-5). The opinions and conclusions are solely those of the authors and should not be considered as representing the opinions or policy of the Social Security Administration or any agency of the Federal Government.

\section{Regents of the University of Michigan}

David A. Brandon, Ann Arbor; Laurence B. Deitch, Bingham Farms; Daniel D. Horning, Grand Haven; Olivia P. Maynard, Goodrich; Rebecca McGowan, Ann Arbor; Andrea Fischer Newman, Ann Arbor; S. Martin Taylor, Gross Pointe Farms; Katherine E. White, Ann Arbor; Mary Sue Coleman, ex officio 


\title{
Eligibility for Social Security Disability Insurance
}

Olivia S. Mitchell

John W.R. Phillips

\begin{abstract}
In order to understand whom among the non-disabled older population experiences a health problem later in life and applies for Social Security Disability Insurance, it is necessary to investigate patterns of coverage and reasons for non-coverage. This paper shows that while the safety net program covers most American workers, a substantial group of older women is not covered. In this sense, the program is not helpful to workers reaching their late 50's and early 60's with health-related problems.
\end{abstract}

\section{Authors' Acknowledgements}

The research reported herein was performed pursuant to a grant from the U.S. Social Security Administration (SSA), to the Michigan Retirement Research Center (MRRC). MRRC project number UM 00-06. Opinions and conclusions are solely those of the authors and should not be construed as representing the opinions or policy of SSA or any agency of the Federal Government or MRRC. This research also received support from the Pension Research Council at the Wharton School (Mitchell). This research is part of the NBER programs on Aging and Labor Economics. (C) 2001 Mitchell and Phillips. JEL Codes: J26 Retirement and Retirement Policies; H55 Social Security and Public Pensions; I12 Disability. 


\section{Eligibility for Social Security Disability Insurance}

\section{Olivia S. Mitchell (Penn and NBER) and John W. R. Phillips (SSA)}

This study is part of a larger project examining how and whether older workers in poor health might use Social Security Disability Insurance (DI) as a path out of the labor market (Mitchell and Phillips, 2000). This topic is an important one, to the extent that proposals to raise the age at which people become eligible for early Social Security benefits will alter the opportunity set available to older workers. Indeed, it is possible that raising the early retirement age might induce some older people to apply for DI benefits in lieu of waiting to receive delayed Social Security retirement payments. We therefore seek to explore potential spillovers of a possible policy change involving raising the early retirement age under OASI. This is of policy interest since many on the verge of retirement are in poor health, and hence some may be likely to spill over onto DI rolls if Social Security early retirement ages were raised. Identifying the characteristics and socioeconomic composition of those who can and cannot apply for DI, those who do apply but are rejected, and those who appeal, can provide policymakers with insight regarding the well-being of the "at risk" population. ${ }^{1}$

The present paper seeks to address one question on this larger research agenda, namely, who is insured for DI versus who is not in late middle age. We further investigate what differences these two groups of people exhibit in terms of socioeconomic and health characteristics. We use the Health and Retirement Study (HRS) linked with administrative data to evaluate peoples' insured status by sex and marital status. Our research shows how the aspects of the SSDI formulas for insured status can leave different population subgroups subject to non-coverage at various stages in their lives.

\footnotetext{
${ }^{1}$ Previous studies on DI application and acceptance patterns include Benitez-Silva et al. (2000), Dwyer et al. (2000), Leonesio et al. (2000), Borsch-Supan (1999), Bound and Burkhauser (1999), Hu et al. (1997), Gruber and Kubik (1997), Burkhauser et al. (1996), Haveman and Wolfe (1984a,b), and Parsons (1980) among others.
} 


\section{Data and Methodology}

We examine our question using data from the nationally representative Health and Retirement Study (HRS), a panel study of older American households first interviewed in 1992 when they were age 51-61 (along with their spouses of any age). In this research, we focus only on baseline information though in other work we follow them through additional interview waves. The HRS survey contains extensive and detailed information on demographic, health, wealth, income, and employment data for respondents and their spouses. It is particularly appropriate for our purposes since the respondent records can link to administrative data on Social Security earnings and pension plan provisions. This linkage allows us to compute respondents' eligibility status for benefits as well as the likely benefit amounts that a worker might receive.

In the present research, we use a subset of the "Task Order Data File" (TODF), a cleaned and merged panel data extract of the age-eligible respondents to the Health and Retirement Study questionnaire devised by the RAND Corporation under contract with the Social Security Administration. In the analysis that follows, we limit the analysis to those who were initially interviewed in 1992 and exclude those who were 60 or older. ${ }^{2}$ These data have been approved for use by SSA researchers under restricted data use protocols. ${ }^{3}$ We further limit the sample to those having linked Social Security earnings records; previous research has indicated that this sample reduction does not produce a biased sample (Levine et al., forthcoming [b]). A final sample restriction limits the analysis to respondents who had not received DI prior to the onset of the survey in 1992. This restriction is imposed to ensure that we are examining workers actually in a position to elect between early retirement and other pathways out of the labor market at older ages. Our ultimate sample size for analysis data set is 6,833 .

\footnotetext{
${ }^{2}$ This age restriction is imposed since after people turn age 65 they are no longer eligible for early retirement - and they could have turned 65 in 1996 or 1997, hence being at least age 66 in 1998.

${ }^{3}$ In this study we use all four waves of the HRS currently available in public or preliminary release status; special permission to link retirement outcomes with restricted data were obtained as required.
} 
Our empirical analysis proceeds in steps. First we combine administrative records and HRS files to derive each person's work path and lifetime insured status for Social Security purposes. Using this information, we next explore the age patterns of coverage for both old-age (OASI) and disability (DI) coverage. Finally, we investigate the socioeconomic and health characteristics that predict who is, and who is not, covered for DI on the verge of retirement. We find that some older people in poor health are not eligible for DI and remain persistently ineligible over their worklives. Our analysis sheds some light on the work patterns leading to this outcome.

\section{Who Is Eligible for DI and Who Is Not?}

Many older American workers are insured for both old-age and DI benefits, but coverage is by no means universal (Mitchell and Phillips, 2000; Levine et al. forthcoming [a]). This is because Social Security rules require that workers must contribute for a long enough period in order to be "fully insured" for old-age benefits, and a somewhat separate set of rules is applied to determine whether someone is "disability insured".

Contributions are made in the form of payroll taxes on earnings from Social Security covered employment. A worker earns Quarters of Coverage (QC) based on annual payroll contributions. ${ }^{4}$ Being fully insured for retirement benefits requires the worker to have a number of QCs equal to the difference between her current age and 22. Therefore, the worker must attain at least $40 \mathrm{QC}$ by age 62 to be eligible for retirement benefits. Once he accumulates $40 \mathrm{QC}$, he will be "forever fully insured" (FFI) for retirement benefits. If he is FFI at age 32, he could stop working in covered employment and still claim retirement benefits at age $62 .^{5}$ To be insured for Social Security Disability Insurance or "DI insured," the worker over age 30 must have earned $20 \mathrm{QC}$ during the

\footnotetext{
${ }^{4}$ For example, the payroll contribution requirement to attain a QC in 2000 was $\$ 780$. Workers can attain a maximum of four QC annually. Though called quarters of coverage, workers can attain all four QC in one calendar quarter if their payroll contributions exceed the earnings requirement for four QC $(\$ 3,120$ at the $2000 \mathrm{QC}$ threshold).

${ }^{5}$ Spouses of fully insured workers are eligible for a spousal benefit regardless of their own work history. Coverage, eligibility, and benefit rules relevant to the HRS cohorts in question appear on the Social Security Administration's web page (www.ssa.gov) or in SSA (1992).
} 
last 40 calendar quarters ending in disability. ${ }^{6}$ In other words, at any given time, an individual could be both fully nor disability insured, he might be fully but not disability insured, or he could be neither. ${ }^{7}$

As a result of these particularities in Social Security program rules, people can move into and out of DI eligibility over their lifetimes, depending on their work patterns. In order to explore what fraction of this pre-retirement population is insured for DI purposes, we examine the administrative files linked with HRS respondent records available to researchers under special restricted access conditions. ${ }^{8}$ Based on these files, we can assess the insured status of respondents for OASI and DI over time.

The resulting eligibility patterns over the worklives of HRS respondents are shown in Figure 1 by age and sex. Results for men (indicated by squares) show that $F F I$ status is low among young men, since most have not yet accumulated the 40 quarters of coverage required for OASI eligibility. During their early 30's however, the vast majority of men - over $80 \%$-become fully insured, with the tally inching up to close to $100 \%$ later in life. The disability insurance pattern is somewhat different for men. More

\footnotetext{
${ }^{6}$ Special rules apply to younger workers. The other requirements to be "disability insured" include (1) having at least 6 QC's and (2) having 1 QC for each year from age 22 to the age of disability (i.e. the worker must be Fully Insured).

${ }^{7}$ A worker could be fully but not DI insured if he had at least ten years of work (so he is fully insured) but lost his disability insurance status due to periods of illness or unemployment.

${ }^{8}$ Because of the confidential nature of the administrative data, researchers may access them only under restricted conditions; see www.umich.edu/ hrswww for details. These files were obtained for a majority of HRS respondents, namely those providing permission to link their survey data with administrative records supplied by the Social Security Administration and also with pension plan descriptions provided by respondents' employers. In a few cases Social Security benefits could not be calculated so the respondent had to be omitted from the analysis. One reason for missing Social Security benefits was that respondents gave permission for the University of Michigan to request their Social Security records, but no match was obtained because their records did not match SSA identification information. Also some age-eligible respondents declined to sign the release form permitting their Social Security data to be matched with the HRS (a handful of the very wealthy, some Blacks, and some Hispanics did not provide consent). Omission of non-match cases might bias results if those who had a matched file differ from those lacking a match; however our own exploratory analysis as well as analysis by Haider and Solon (2000) finds little evidence that results are biased. More information regarding Social Security earnings and benefits data for HRS respondents can be found in Mitchell et al. (2000).
} 
than $70 \%$ achieve coverage for DI purposes by the time they are in their early 20 's, and the rates rise gradually into the mid-40's age range. After that point, however, DI coverage rates subside somewhat, as work patterns become more erratic into the $50 \mathrm{~s}$ and 60's. Lower DI coverage could potentially be problematic for this older group, to the extent that older workers tend to have health problems and are often more seriously injured when they sustain workplace accidents (Mitchell 1988).

\section{Figure 1 here}

The patterns for women (represented by circles) are quite different, as Figure 1 indicates. Both sexes start with very low FI rates at young ages, but whereas men's rise quickly after age 25 and asymptote in their 40's, women's rise more slowly with age and do not level off, instead rising all the way to age 65 . Even at older ages, nevertheless, women are 20 percentage points less likely than men to be fully insured. Even more striking is the sex difference in DI rates for this sample. Women's DI insured status is only $40 \%$ in early work life; then it falls below this threshold until around age 40, and only rebounds when market work again becomes significant in their lives. After that, women remain much less likely to be insured for DI purposes, with the uncovered group of women workers never shrinking below about one-third in later life. Thus these results indicate that working women are less well-protected by Social Security disability insurance than are working men due to their more episodic labor market attachment. A substantial subset of both men and women is not DI insured in later life, but the gap is more important for women than for men. ${ }^{9}$

Differences in FI and DI insurance patterns by sex and marital status are given in Figure 2 (marital status is measured as of Wave 1 of the HRS survey, so some nonmarried persons were previously married). Among men, there are virtually no differences in coverage patterns by marital status, as the figure reveals. Among women, however, the patterns are distinctly different for married and unmarried respondents. In

\footnotetext{
${ }^{9}$ Many individuals not covered by SSDI might be eligible for the Supplemental Security Income program (SSI). SSI pays benefits to individuals who are either disabled or over age 65 and meet the income and asset tests. More information on eligibility criteria and benefits for the SSI program can be found in SSA (1992). In future research, we will examine the proportion of those uncovered for SSDI who meet the income and asset criteria for SSI.
} 
particular, married women are less likely to be DI insured and FFI early in life, and this

gap favoring nonmarried women grows after about the mid-30s. Clearly the HRS women not married in their 50's had substantially more workforce attachment during their entire lives, as compared to married women in late middle age. Nevertheless, even among the nonmarried women, the peak DI insured rate of just over $70 \%$ is substantially lower than for men.

Figure 2 here

Three different criteria must be met when determining whether or not a respondent is DI insured. These may be elaborated by focusing on the fraction of people not insured for DI who "fail" what we term three "tests" over their worklives. Accordingly, we define DITest 1 as indicative of whether the individual has sufficient recent quarters of coverage (i.e. if his age was over 30, did he have $>=20$ QC in last 10 years; if his age was 30 or younger, did he have $\mathrm{QC}>=($ age-22)*2). DITest 2 refers to the fully insured condition, indicating whether the respondent had enough total QC $>=($ age22). Finally, DITest 3 is the most lenient criterion, indicting whether the respondent had at least $6 \mathrm{QC}$ by a given age.

The results for our HRS respondents appear in Figure 3. For most of the DI ineligible respondents, they "fail" due to DITest1, the recency criterion. Furthermore this threshold proves to be a persistent barrier over the worklife, with only a slight drop for people in their 50's. Therefore not having enough recent quarters of coverage proves to be a substantial barrier to DI coverage at all ages, including in the later portion of the worklife.

Figure 3 here

DITest 2 - the fully insured test - applies to almost $30 \%$ of both men and women in their younger years. In later life, however, this test eliminates fewer and fewer men, but binds for increasingly larger numbers of women. Thus, some $60 \%$ of the noncovered women are unable to meet the long-term work requirements implicit in the second threshold by the time they are in their 50's and 60's. Finally, Figure 3 indicates that DITest3 has the least "bite" for both men and women, though the effect is smaller for men (roughly zero) as compared to women (where some $15 \%$ of women do not meet this 
test even by their mid-60's). Again, neither of these effects differs markedly by marital status.

\section{Multivariate Analysis of DI Coverage}

To explore the factors associated with being DI insured among the HRS respondents, we next provide empirical results of an analysis of coverage patterns. Here we use a Probit model to assess the various contributions of socioeconomic status (age, race and ethnicity, education, sex, marital status and history, number of children, income and wealth, and a range of health variables ranging from self-reported overall health, to health limitations). Summary statistics appear in Table 1. Inasmuch as Probit coefficients are not particularly informative, we instead report the estimated result of response magnitudes evaluated using actual data along with the statistically significance level of the underlying coefficients. Results appear in Table 2.

\section{Tables 1 and 2 here}

One clear message from the set of models examined is the substantial stability in estimates generated. Thus age has a negative effect on the probability of being DI insured, holding constant other factors. ${ }^{10}$ The marginal effect is such that a one-year older respondent, ceteris paribus, would have almost a 1-percentage point lower probability of being DI insured versus not. Married respondents are more than 10 percentage points less likely to be covered, even after controlling on other factors. Having ever experienced a divorce increases the probability of being DI insured, while the number of children in the family reduces the likelihood of being DI insured. The impact of being female is negative at -0.22 , with relatively little variation in estimates across models. The

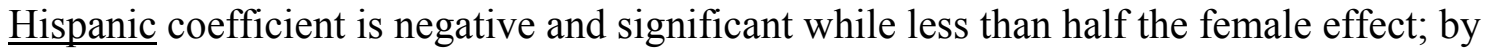
contrast, the Black coefficient is not statistically significant. Both income and wealth (in natural $\log$ form) are positively associated with the probability of being DI insured, with the non-capital income association more strongly positive and about four times as large as the non-Social Security wealth effect. ${ }^{11}$

\footnotetext{
${ }^{10}$ The sample includes only respondents younger than 61 in 1992.

${ }^{11}$ Non-capital income is total household income less income from capital. Non-Social Security wealth is the present discounted value of all wealth less Social Security wealth.
} 
One of the key features of the HRS is its richness of information on health problems facing older Americans. Accordingly, we explore six measures of health problems intended to capture alternative dimensions of older workers' physical and mental functioning. First, we evaluate a measure widely used by social scientists called here "Health (Poor $\mid$ Bad)," which refers to respondents' own evaluation of whether their health is excellent, very good, or good (tabulated as $=0$ ) or fair or poor (tabulated as $=1$ ). Various researchers have suggested this is a good measure of HRS respondent actual health status (Dwyer and Mitchell, 1999). We also use a self-report of work preventing disability ( $=1$ if disability prevents work). Research by Benitez-Silva et al. (2000) implies that this variable is a good predictor of medical eligibility for SSDI. Other health variables we examine include a variable summarizing doctor-diagnosed conditions, a self-report of work-limiting disability, an identifier for respondent with any $A D L$ difficulties, and the respondent's view of his chance of living to 75 or beyond.

Table 2 shows that being in poor health is systematically associated with a lower probability of the respondent being eligible for DI coverage. This result is robust to the particular health variable elected. For instance, having self-reported "fair/poor" health is associated with 14 percentage points lower chance of being DI covered. The effect is about the same size for people reporting any ADL problem. Larger negative estimates hold for those whom disability limits or prevents work. Across the board, therefore, older workers suffering health problems in later life appear less likely to be insured for SSDI, despite perhaps having a greater need for such benefits than their healthier counterparts.

A question that arises from the multivariate analysis is whether the effects of characteristics on DI insured status are the same for men and women. Intuition suggests that many of the results from Table 2 regarding marriage and family issues might differ for the women of this cohort. Furthermore, Figure 2 suggested that eligibility tests have differential impacts across the sexes. Men are not only more likely to be insured for both OASI and DI, but also their marital status does not appear to influence their insured

The wealth measure includes the net value of stocks, bonds, checking/savings accounts, $\mathrm{CD}$, businesses owned, IRA, real estate holdings (including residence), vehicles owned, employer pensions, and "other" assets. 
status. To examine this in the multivariate framework, we interact all variables in the equations by the FEMALE indicator and perform a statistical test (specifically, a likelihood ratio test) to determine whether or not the interactions are meaningful. The results appear in Table 3.

\section{Table 3 here}

Conventional likelihood ratio tests indicate that the augmented model has a better statistical "fit" than the simpler equations. While some characteristics do not affect women differently than men, many do. As expected the family structure variables (married, divorced, and number of children) are significant with the expected signs for women, but these now become statistically insignificant for men. While black and Hispanic women are more likely to be DI insured, black and Hispanic men are less likely to be insured. Though poor health still is associated with a lower chance of being DI insured, the effect does not appear to work differentially among women.

The finding that older respondents in poor health are less likely to be DI insured is worthy of further analysis. In order to determine the circumstances of individuals who are both uninsured for DI and suffering from health problems, we subdivide respondents according to their DI insured status and whether they report a work limiting disability: Table 4 indicates that nine percent of our sample is both work limited and uninsured. Individuals in this group are by almost every measure worse off than their counterparts. They are less likely to have the support of a spouse since fewer are marred and more report being widowed. This group also reports the highest incidence of poor health. Half of those uninsured for DI and also have a work limiting disability indicate they are work-

prevented because of their health. Among those who report a work limiting disability but are DI insured, only one-quarter report a work preventing disability. Finally, those who are uninsured and in poor health have substantially lower income and wealth than all other groups.

Table 4 here

\section{Conclusions and Discussion}

This research asks what fraction of the population on the verge of retirement is, and is not, insured for DI purposes, and to the extent determinable, what explains their 
lack of DI receipt. We find that a substantial percentage of men, and an even greater fraction of women, is not DI-insured in midlife. The factors that seem to be associated with higher coverage rates are not identical for men and women. Family structure plays an important role in the insured status of women, but it has little effect on men's insured status. It appears as though marriage and childbearing make women more susceptible to falling out of DI insured status than men. Wealth, income, and good health improve the likelihood of being DI insured for both men and women.

A finding of particular concern is that those in poor health are less likely to be DI insured than those in good health. Our examination of individuals by DI insured and work limiting disability status shows that those who are uninsured and also have a work limiting disability experience the lowest level of socioeconomic well being. Some of those who are uninsured for DI and in poor health might qualify for SSI. Determining what fraction that would be covered by the SSI program and the extent to which their well being is affected is one of several related topics for future research.

The next stage of our analysis will examine the subset of people that is DI insured and compare them with those who apply for DI. We will also investigate who is granted DI benefits and how they compare in terms of socioeconomic and health characteristics to those who are rejected. ${ }^{12}$

Policy implications from our preliminary findings are premature. Nevertheless it is reasonable to conclude that a significant number of Americans (around $20 \%$ of women in later life) are uninsured for disability insurance under Social Security. This gives rise to concern as to how well the safety net works for older infirm workers. Further, we find that those who in poor health are less likely to be DI insured, implying that many in need are not eligible for benefits. This fact is of particular interest given the overall objective of our research. Any approach that attempts to determine medical eligibility for DI without controlling for DI insured status might "include" a substantial number of people who are actually not insured for DI and hence ineligible for benefits. In our HRS sample, $65 \%$ of those who reported a work-preventing disability in 1992 were not DI insured in 1992. Such an omission could lead to an overestimate of those who could claim DI.

\footnotetext{
${ }^{12}$ We further hope to assess whether the results from this analysis are sensitive to the way in which sample attrition is handled.
} 


\section{References}

Benitez-Silva, Hugo, Moshe Buchinsky, Hiu Man Chan, Sofia Cheidvasser, and John Rust. "How Large is the Bias in Self-Reported Disability?" NBER Working Paper No. W7526. February 2000.

Borsch-Supan, Axel. "Incentive Effects of Social Security Under an Uncertain Disability Option.” NBER WP 7339. September 1999.

Bound, John and Richard Burkhauser. "Economic Analysis of Transfer Programs Targeted on People with Disabilities." Handbook of Labor Economics. Eds. Orley Ashenfelter and David Card. New York: Elsevier, 1999: 2417-2528.

Burkhauser, Richard V., Kenneth A. Couch, and John W. Phillips. "Who Takes Early Social Security Benefits: The Economic and Health Characteristics of Early Beneficiaries," The Gerontologist, 36(6). 1996: 789-799.

Dwyer, Debra and Olivia S. Mitchell. "Health Problems as Determinants of Retirement: Are Self-Rated Measures Endogenous?” Journal of Health Economics (18) 1999:173-193.

Dwyer, Debra, Jainting Hu, Denton R. Vaughan, and Bernard Wixon, "Counting the Disabled: Using Survey Self-reports to Estimate Medical Eligibility for Social Security's Disability Programs," Office of Research, Evaluation, and Statistics Working Paper 20, Social Security Administration, Washington, DC, September 2000.

Gruber, Jonathan and Jeffrey Kubik. "Disability Insurance Rejection Rates and the Labor Supply of Older Workers." Journal of Public Economics. 64, 1997:1-23.

Gustman, Alan S., Olivia S. Mitchell and Thomas Steinmeier. "The Role of Pensions in the Labor Market." Industrial and Labor Relations Review 47 (3) 1994: 417-438.

Haider, Steven and Gary Solon. "Nonrandom Selection in the HRS Social Security Earnings Sample." RAND Working Paper Series 00-01, February 2000.

Haveman, Robert and Barbara Wolfe. "The Decline of Male Labor Force Participation: Comment." JPE 92(3): 1984: 532-541. [a]

Haveman, Robert and Barbara Wolfe. "Disability Transfers and Early Retirement: A Causal Relationship?" Journal of Public Economics 21, 1984: 47-66. [b]

$\mathrm{Hu}$, Jianting, Kajal Lahiri, Denton Vaughan, and Bernard Wixon. "A Structural Model of Social Security's Disability Determination Process.” ORES Working Paper 72, Social Security Administration, August 1997.

Leonesio, Michael V., Denton R. Vaughan, and Bernard Wixon. "Early Retirees Under Social Security: Health Status and Economic Resources". Social Security Administration, ORES Working Paper 86, August 2000.

Levine, Phillip B., Olivia S. Mitchell, John W. Phillips. “A Benefit of One’s Own: Older Women's Retirement Entitlements Under Social Security”. Social Security Bulletin. Forthcoming. [a]

Levine, Phillip, Olivia S. Mitchell, and John Phillips. "Worklife Determinants of Retirement Income Differentials Between Men and Women." In Zvi Bodie, Brett Hammond, and Olivia S. Mitchell, Eds. Innovations in Financing Retirement. Pension Research Council. Philadelphia, PA: University of Pennsylvania Press. Forthcoming. [b] 
Mitchell, Olivia S. "The Relation of Age to Workplace Injury." Monthly Labor Review 111, July 1988: 8-13.

Mitchell, Olivia S, Jan Olson, and Thomas Steinmeier. "Earnings and Projected Benefits." In Forecasting Retirement Needs and Retirement Wealth. Eds. O.S. Mitchell, B. Hammond, and A. Rappaport. Pension Research Council. Philadelphia, PA: University of Pennsylvania Press, 2000: 68-94.

Mitchell, Olivia S. and John W.R. Phillips. "Retirement Responses to Early Social Security Benefit Reductions.” NBER WP, 2000.

Parsons, Donald. "The Decline of Male Labor Force Participation.” JPE 88(1): 1980: 117-134.

Smith, Ralph. "Raising the Earliest Eligibility Age for Social Security Benefits." Congressional Budget Office, Washington, D.C. January 1999.

Social Security Administration (SSA). Annual Statistical Supplement to the Social Security Bulletin. US Department of Health and Human Services. Washington, DC: US GPO, 1992. 
Figure 1: Percent DI and OASI Insured by Age and Sex

Source: Authors' calculations using HRS analysis sample (see text)

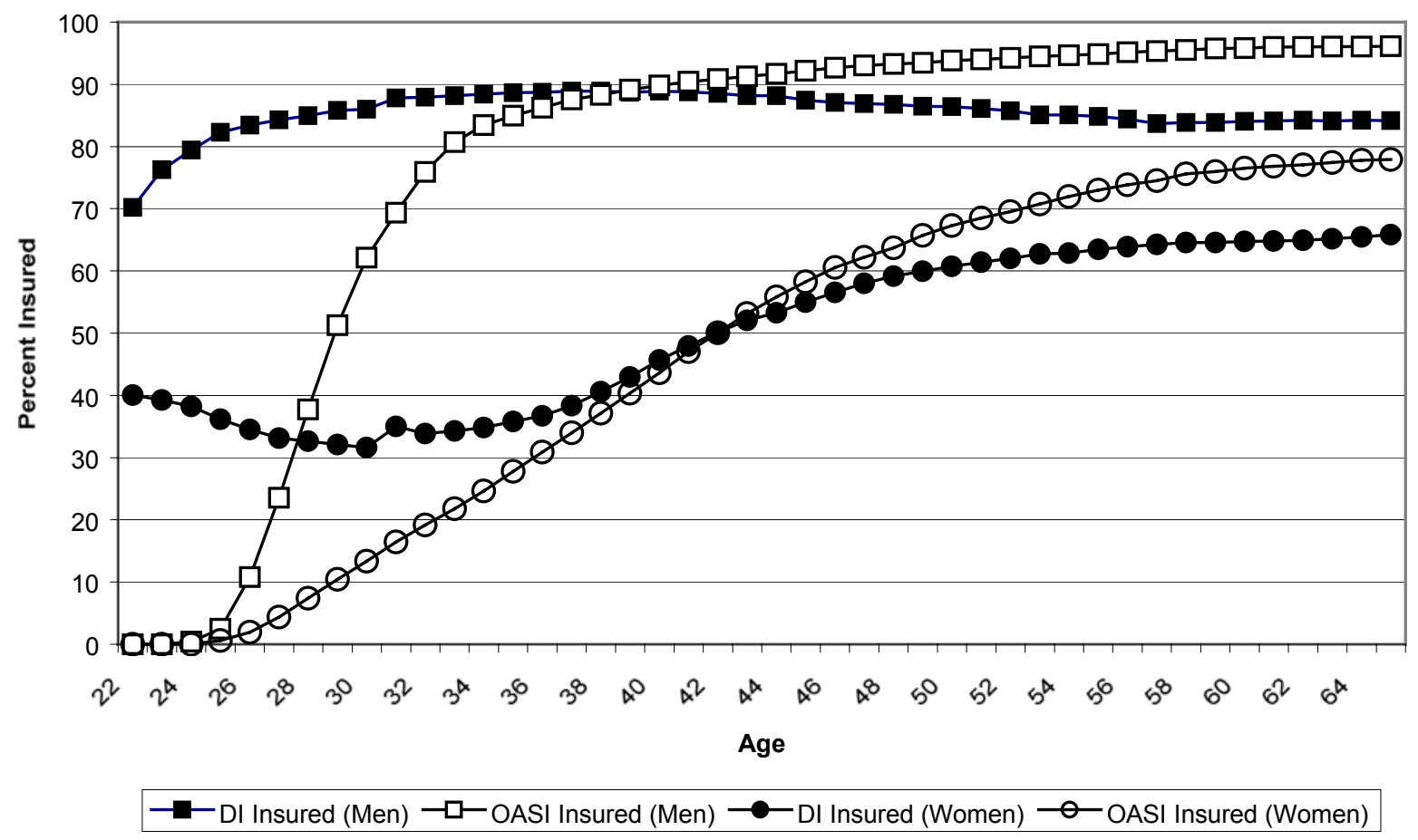

Note: All observations weighted by Wave 1 sample weights. 
Figure 2: Percent DI and OASI Insured by Sex, Age, and Marital Status Source: Authors' calculations using HRS analysis sample.
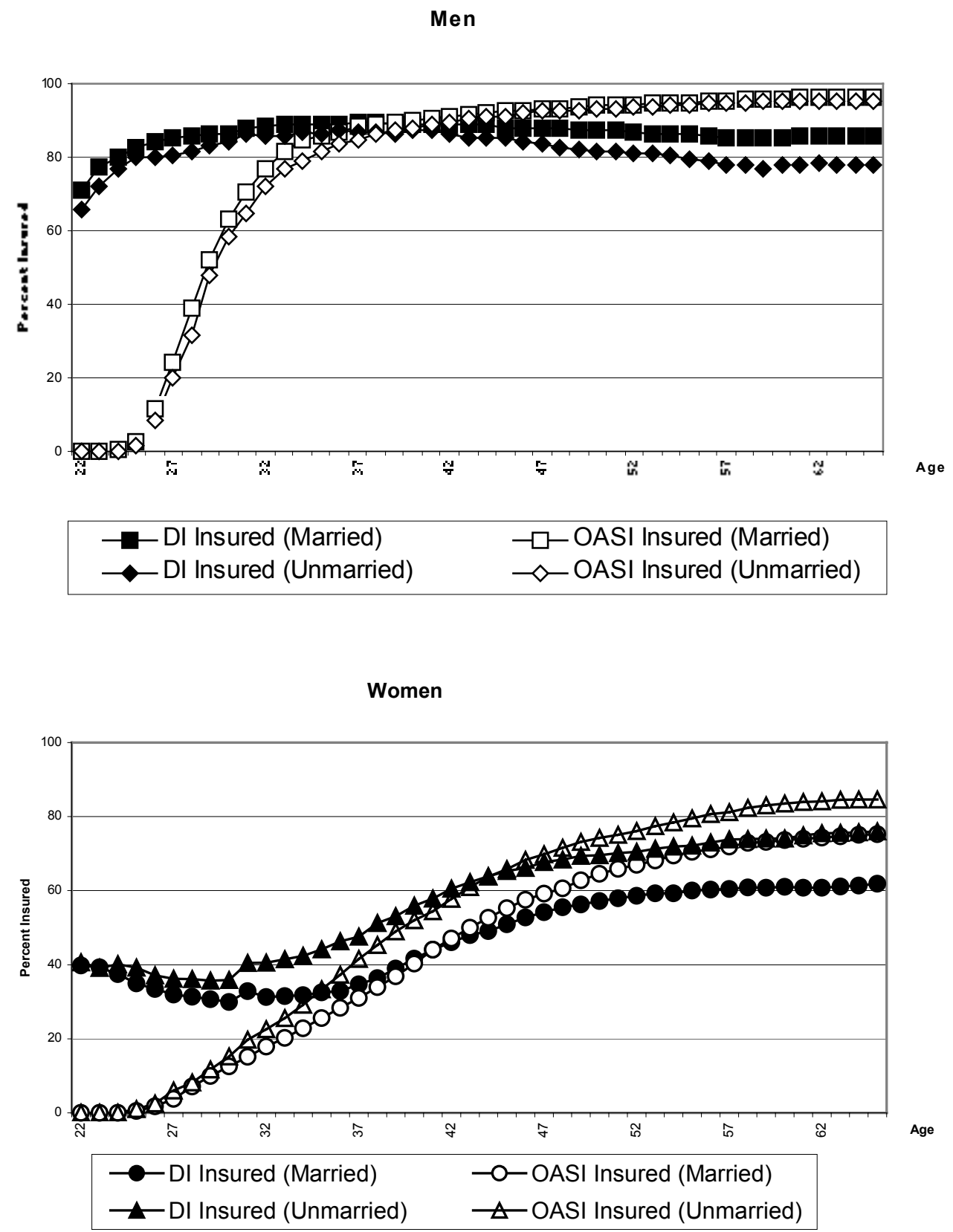

Note: All observations weighted by Wave 1 sample weights. 
Figure 3. Criteria Restricting DI Coverage by Sex and Marital Status

Source: Authors' calculations using HRS analysis sample.
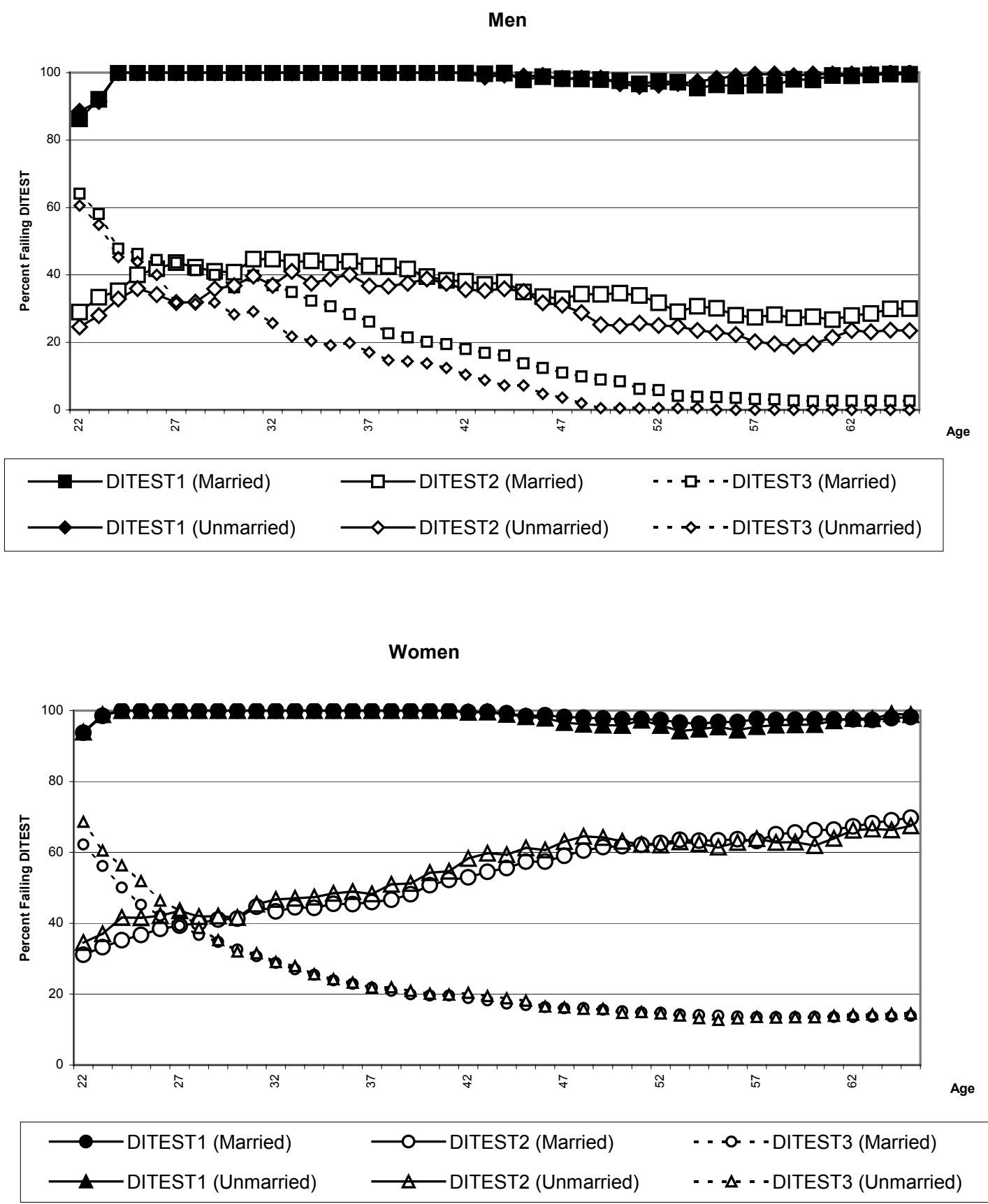

Note: All observations weighted by Wave 1 sample weights.

Variable definitions:

DII $\%$ SSDI insured at age $\mathrm{X}$

FFI $\quad \%$ Forever Fully Insured for retirement benefits at age X (i.e. 40+ QC)

DITEST1 \% NOT SSDI insured because, at age $\mathrm{X}$ : if $>$ age 30 , had $<20$ QC in last 10 years; if $<31$ had QC $<(\text { DIage- } 22)^{*} 2$.

DITEST2 \% NOT SSDI insured because, at age $\mathrm{X}, \mathrm{QC}<$ (Diage-22) [Fully Insured condition].

DITEST3 \% NOT SSDI insured because $\mathrm{QC}<6$ at age $\mathrm{X}$ 
Table 1: Summary Statistics: HRS Respondents, by Sex

\begin{tabular}{|c|c|c|c|}
\hline \multirow{2}{*}{$\begin{array}{c}\text { Variable } \\
\text { Name }\end{array}$} & \multirow{2}{*}{$\begin{array}{c}\text { Variable } \\
\text { Definition }\end{array}$} & Men & Women \\
\hline & & \multicolumn{2}{|c|}{ Mean } \\
\hline$\overline{\text { Age }}$ & Age (years) in 1992 & 55 & 55 \\
\hline Married & Married (1=yes) in 1992 & 0.81 & 0.72 \\
\hline Ever Divorced & Ever divorced & 0.34 & 0.31 \\
\hline Ever Widowed & Ever Widowed & 0.04 & 0.13 \\
\hline Number of Children & Number of Children & 3.1 & 3.3 \\
\hline Black & Black (1=yes) & 0.09 & 0.1 \\
\hline Hispanic & Hispanic (1=yes) & 0.06 & 0.06 \\
\hline Education & Years of Education & 12.6 & 12.3 \\
\hline Working & Working (1=yes) in 1992 & 0.82 & 0.63 \\
\hline FFI1992 & $40+$ Quarters of Coverage in 1992 & 0.95 & 0.72 \\
\hline DII1992 & SS Disability Insured in 1992 & 0.83 & 0.61 \\
\hline Health Poor/Bad & Self Report Fair/Poor Health & 0.16 & 0.18 \\
\hline $\mathrm{P}($ Live to 75$)$ & Prob. Live to $75(\%)$ & 63.1 & 66.9 \\
\hline Diagnosed Conditions & Sum Health Conditions & 0.99 & 1.16 \\
\hline Difficult ADLs & Summary of ADL difficulties & 0.06 & 0.07 \\
\hline Work Limiting Disability & Disability Limits Work & 0.17 & 0.18 \\
\hline \multirow[t]{2}{*}{ Work Preventing Disability } & Disability Prevents Work & 0.06 & 0.07 \\
\hline & & \multicolumn{2}{|c|}{ Median } \\
\hline Non-SS Wealth** & HH Total Wealth Less SS & $\$ 199,828$ & $\$ 171,372$ \\
\hline OASI & HH Social Security Wealth & $\$ 148,670$ & $\$ 151,742$ \\
\hline Non-Capital Income** & HH Income Less Capital Income & $\$ 42,000$ & $\$ 32,000$ \\
\hline \multirow[t]{2}{*}{ Income } & Total HH Income & $\$ 46,000$ & $\$ 35,439$ \\
\hline & & \multicolumn{2}{|c|}{ Observations } \\
\hline Sample Size & Subset of HRS sample* & 3,147 & 3,686 \\
\hline
\end{tabular}

Source: Authors' computations from HRS Wave 1, weighted by HRS sample weights.

All dollar values in $1992 \$$.

* Sample contains all age eligible respondents who have a Social Security link, were not receiving DI prior to 92, and were under age 67 in 1998.

**Non-capital income is total household income less income from capital. Non-Social Security wealth is the present discounted value of all wealth less Social Security wealth. The wealth measure includes the net value of stocks, bonds, checking/savings accounts, $\mathrm{CD}$, businesses owned, IRA, real estate holdings (including residence), vehicles owned, employer pensions, and "other" assets. 
Table 2: Probit Estimates of the Probability of being DI Insured

\begin{tabular}{|c|c|c|c|c|c|c|}
\hline \multirow{2}{*}{$\begin{array}{l}\text { Explanatory } \\
\text { Variable }\end{array}$} & \multicolumn{6}{|c|}{$\begin{array}{l}\text { Dependent Variable: DI Insured at Wave } 1 \\
\qquad \mathrm{dF} / \mathrm{dx}\end{array}$} \\
\hline & (a) & (b) & (c) & (d) & (e) & (f) \\
\hline Age & $-0.01 *$ & $-0.01 *$ & $-0.01 *$ & $-0.01 *$ & $-0.01 *$ & $-0.01 *$ \\
\hline Married & $-0.10^{*}$ & $-0.10^{*}$ & $-0.10^{*}$ & $-0.10^{*}$ & $-0.10^{*}$ & $-0.10^{*}$ \\
\hline Ever Divorced & $0.06^{*}$ & $0.06^{*}$ & $0.06^{*}$ & $0.06^{*}$ & $0.06^{*}$ & $0.05^{*}$ \\
\hline Ever Widowed & 0.01 & 0.01 & 0.01 & 0.01 & 0.01 & 0.00 \\
\hline Number of Children & $-0.01 *$ & $-0.01 *$ & $-0.01 *$ & $-0.01 *$ & $-0.01 *$ & $-0.01 *$ \\
\hline Female & $-0.22 *$ & $-0.22 *$ & $-0.22 *$ & $0.21 *$ & $-0.22 *$ & $-0.22 *$ \\
\hline Black & 0.00 & -0.01 & 0.00 & -0.00 & -0.01 & -0.01 \\
\hline Hispanic & $-0.08^{*}$ & $-0.10^{*}$ & $-0.10^{*}$ & $-0.10^{*}$ & $-0.08^{*}$ & $0.09^{*}$ \\
\hline Education (yrs) & -0.00 & -0.00 & -0.00 & -0.00 & -0.00 & -0.00 \\
\hline Health (poor|bad) & $-0.14 *$ & -- & -- & -- & -- & -- \\
\hline Work Limiting Disability & -- & $-0.21 *$ & -- & -- & -- & -- \\
\hline Work Preventing Disability & -- & -- & $-0.33^{*}$ & -- & -- & -- \\
\hline Diagnosed Conditions & -- & -- & -- & $-0.05^{*}$ & -- & -- \\
\hline Difficult ADLs & -- & -- & -- & -- & $-0.11^{*}$ & -- \\
\hline Self-report P(Live to 75) & -- & -- & -- & -- & & $0.001 *$ \\
\hline Ln(non-capital income) & $0.043^{*}$ & $0.03 *$ & $0.03 *$ & $0.04 *$ & $0.04 *$ & $0.04 *$ \\
\hline Ln(non-Social Security wealth) & $0.011^{*}$ & $0.01 *$ & $0.01 *$ & $0.01 *$ & $0.01 *$ & 0.01 \\
\hline $\mathrm{N}=6,833$ & & & & & & \\
\hline LL & -3733.77 & -3683.35 & -3673.5 & -3732.2 & -3747.26 & -3642.08 \\
\hline Pseudo R2 & 0.10 & 0.12 & 0.12 & 0.10 & 0.10 & 0.10 \\
\hline
\end{tabular}

Source: Authors' computations from HRS Wave 1, weighted by HRS sample weights. See Table 1 .

Notes: $\mathrm{dF} / \mathrm{dx}$ computed for qualitative variable changing from 0 to 1 .

- signifies variable omitted from equation.

* Indicates $Z$ test rejects underlying coefficient $=0$ at $95 \%$ confidence level. 
Table 3: Probit Estimates of the Probability of being DI Insured with Female Interactions

\begin{tabular}{|c|c|c|c|c|c|c|}
\hline \multirow{2}{*}{$\begin{array}{l}\text { Explanatory } \\
\text { Variable }\end{array}$} & \multicolumn{6}{|c|}{$\begin{array}{l}\text { Dependent Variable: DI Insured at Wave } 1 \\
\qquad \mathbf{d F} / \mathbf{d x}\end{array}$} \\
\hline & (a) & (b) & $(\mathrm{c})$ & (d) & (e) & (f) \\
\hline Age & $-0.01 *$ & $-0.01 *$ & $-0.01 *$ & $-0.01 *$ & $-0.01 *$ & $-0.01 *$ \\
\hline Married & 0.01 & 0.00 & 0.00 & 0.01 & 0.01 & 0.01 \\
\hline Ever Divorced & 0.00 & -0.01 & 0.00 & 0.00 & 0.00 & -0.01 \\
\hline Ever Widowed & 0.02 & 0.02 & 0.03 & 0.02 & 0.02 & 0.02 \\
\hline Number of Children & 0.00 & 0.00 & 0.00 & 0.00 & 0.00 & 0.00 \\
\hline Female & $-0.75^{*}$ & $-0.76^{*}$ & $-0.76^{*}$ & $-0.75^{*}$ & $-0.77 *$ & $-0.80 *$ \\
\hline Black & $-0.10^{*}$ & $-0.11 *$ & $-0.09 *$ & $-0.11 *$ & $-0.10^{*}$ & $-0.11 *$ \\
\hline Hispanic & $-0.15^{*}$ & $-0.17 *$ & $-0.16^{*}$ & $-0.17 *$ & $-0.14 *$ & $-0.15^{*}$ \\
\hline Education (yrs) & $-0.02 *$ & $-0.02 *$ & $-0.02 *$ & $-0.01 *$ & $-0.01 *$ & $-0.01 *$ \\
\hline Health (poor|bad) & $-0.14^{*}$ & -- & -- & -- & -- & -- \\
\hline Work Limiting Disability & -- & $-0.22^{*}$ & -- & -- & -- & -- \\
\hline Work Preventing Disability & -- & -- & $-0.39 *$ & -- & -- & -- \\
\hline Diagnosed Conditions & -- & -- & -- & $-0.05^{*}$ & -- & -- \\
\hline Difficult ADLs & -- & -- & -- & -- & $-0.16^{*}$ & -- \\
\hline Self-report P(Live to 75) & -- & -- & -- & -- & -- & 0.00 \\
\hline Ln(non-capital income) & $0.02 *$ & $0.02 *$ & $0.02 *$ & $0.03 *$ & $0.03 *$ & $0.03 *$ \\
\hline Ln(non-Social Security wealth) & $0.01 *$ & $0.01 *$ & $0.01 *$ & $0.02 *$ & $0.01 *$ & $0.02 *$ \\
\hline \multicolumn{7}{|l|}{ Variable Interactions w/FEMALE } \\
\hline Age & $0.01 *$ & $0.01 *$ & 0.01 & $0.01 *$ & $0.01 *$ & $0.01 *$ \\
\hline Married & $-0.18^{*}$ & $-0.17 *$ & $-0.17 *$ & $-0.18^{*}$ & $-0.18^{*}$ & $-0.18^{*}$ \\
\hline Ever Divorced & $0.09 *$ & $0.10^{*}$ & $0.10^{*}$ & $0.10^{*}$ & $0.09 *$ & $0.09 *$ \\
\hline Ever Widowed & -0.03 & -0.04 & -0.04 & -0.03 & -0.03 & -0.04 \\
\hline Number of Children & $-0.01 *$ & $-0.02 *$ & $-0.02 *$ & $-0.01 *$ & $-0.01 *$ & $-0.01 *$ \\
\hline Black & $0.13^{*}$ & $0.13 *$ & $0.12 *$ & $0.13^{*}$ & $0.13^{*}$ & $0.13^{*}$ \\
\hline Hispanic & $0.09 *$ & $0.09 *$ & $0.09 *$ & $0.09 *$ & 0.07 & 0.08 \\
\hline Education (yrs) & $0.02 *$ & $0.02 *$ & $0.03 *$ & $0.02 *$ & $0.02 *$ & $0.02 *$ \\
\hline Health (poor $\mid$ bad) & -0.01 & -- & -- & -- & -- & -- \\
\hline Work Limiting Disability & -- & 0.01 & -- & -- & -- & -- \\
\hline Work Preventing Disability & -- & -- & 0.07 & -- & -- & -- \\
\hline Diagnosed Conditions & -- & -- & -- & 0.00 & -- & -- \\
\hline Difficult ADLs & -- & -- & -- & -- & $0.09 *$ & -- \\
\hline Self-report P(Live to 75) & -- & -- & -- & -- & & 0.00 \\
\hline Ln(non-capital income) & $0.02 *$ & $0.02 *$ & $0.02 *$ & $0.02 *$ & $0.02 *$ & $0.02 *$ \\
\hline Ln(non-Social Security wealth) & 0.00 & 0.00 & 0.00 & -0.01 & 0.00 & 0.00 \\
\hline \multicolumn{7}{|l|}{$\mathrm{N}=6,833$} \\
\hline LL & -3660.31 & -3608.76 & -3598.14 & -3656.46 & -3670.73 & -3570.41 \\
\hline Pseudo R2 & 0.12 & 0.13 & 0.14 & 0.12 & 0.12 & 0.11 \\
\hline Likelihood Ratio Test (chi sqr)** $^{* *}$ & $146.93 *$ & $149.17^{*}$ & $150.72 *$ & $151.48^{*}$ & $153.07^{*}$ & $143.32^{*}$ \\
\hline
\end{tabular}

Source: Authors' computations from HRS Wave 1, weighted by HRS sample weights.

Note: $\mathrm{dF} / \mathrm{dx}$ computed for $\mathrm{X}$ variable changing from 0 to 1 .

* Indicates $\mathrm{Z}$ test rejects underlying coefficient $=0$ at $95 \%$ confidence level.

** Chi square likelihood ratio test between interaction model and model without interactions. Significance implies improvement in prediction from interaction model. 
Table 4: Socioeconomic Characteristics by Self-reported Work Limiting Disability and SSDI Insured Status in 1992

\begin{tabular}{|c|c|c|c|c|}
\hline \multirow[b]{2}{*}{ Variables } & \multicolumn{2}{|c|}{ Work Limiting Disability } & \multicolumn{2}{|c|}{ No Work Limiting Disability } \\
\hline & SSDI Insured & Not SSDI Insured & SSDI Insured & Not SSDI Insured \\
\hline \multicolumn{5}{|l|}{ Demographic (means) } \\
\hline Married & 0.73 & 0.65 & 0.76 & 0.82 \\
\hline Ever Divorced & 0.38 & 0.37 & 0.34 & 0.25 \\
\hline Ever Widowed & 0.09 & 0.14 & 0.08 & 0.09 \\
\hline Number of Children & 3.43 & 3.64 & 3.08 & 3.37 \\
\hline Female & 0.43 & 0.68 & 0.46 & 0.74 \\
\hline Black & 0.09 & 0.17 & 0.08 & 0.08 \\
\hline Hispanic & 0.06 & 0.08 & 0.05 & 0.08 \\
\hline Education (yrs) & 11.72 & 10.97 & 12.73 & 12.40 \\
\hline Diagnosed Conditions & 1.74 & 2.26 & 0.87 & 0.95 \\
\hline Difficult ADLs & 0.20 & 0.43 & 0.01 & 0.01 \\
\hline Work Preventing Disability & 0.26 & 0.51 & 0.00 & 0.00 \\
\hline FFI1992 & 0.99 & 0.48 & 0.99 & 0.39 \\
\hline \multicolumn{5}{|l|}{ Income/Wealth (medians) } \\
\hline Non-Capital Income & $\$ 29,650$ & $\$ 15,540$ & $\$ 41,000$ & $\$ 35,000$ \\
\hline Non-Social Security Wealth & $\$ 121,371$ & $\$ 57,635$ & $\$ 197,507$ & $\$ 253,080$ \\
\hline Sample Size & 644 & 611 & 4,179 & 1,399 \\
\hline
\end{tabular}

Source: Authors' computations from HRS Wave 1, weighted by HRS sample weights. 